\title{
Alvorlig skadede overført til universitetssykehus
}

\author{
Sammendrag \\ Bakgrunn. Vi har analysert diagnostikk \\ og stabiliserende kirurgi hos hardt \\ skadede som ble overført fra lokal- \\ sykehus til universitetssykehus i akutt- \\ fasen. Hensikten var å avdekke forbed- \\ ringsmuligheter i den regionale trau- \\ mebehandlingen.
}

\section{Materiale og metode. Materialet} omfatter samtlige hardt tilskadekomne (Injury Severity Score (ISS) > 15) som ble overført fra lokalsykehus til Universitetssykehuset Nord-Norge i perioden 1.1 2006-31.12. 2007. Diagnostikk, skadeomfang og behandling det første døgnet etter overflytting ble kartlagt ved gjennomgang av universitetssykehusets pasientjournal. Nødkirurgiske inngrep er definert i henhold til planene for et nasjonalt traumesystem.

Resultater. Seks av totalt 74 pasienter gjennomgikk nødkirurgi ved lokalsykehuset, i form av thoraxdreninnleggelse og bruddfiksasjoner. Åtte gjennomgikk nødkirurgi etter ankomst universitetssykehuset, i form av thoraxdrenasje, hemostatisk buk- og bekkenpakking og bruddfiksasjoner. 66 av de 74 ble undersøkt med CT ved lokalsykehuset, hvorav 37 med CT multitraumeserie (CT caput, nakke, thorax, abdomen, bekken). Av de 62 som ved lokalsykehuset gjennomgikk CT caput, ble det hos ti ikke gjort samtidig bildediagnostikk av cervikalcolumna, og åtte av 55 gjennomgikk CT thorax/buk/bekken uten at det ble brukt intravenøst kontrastmiddel.

Fortolkning. Lokalsykehusenes håndtering av alvorlig tilskadekomne kan sannsynligvis forbedres gjennom mer planmessig bildediagnostikk, ved å senke terskelen for visse nødkirurgiske prosedyrer og ved systematisk kontakt med universitetssykehus tidlig i forløpet.

\section{Trond Dehli}

trond.dehli@unn.no

Hjerte-, lunge- og karkirurgisk avdeling

Anna Bågenholm

Liv-Hege Johnsen

Radiologisk avdeling

\section{Svein Are Osbakk}

Knut Fredriksen

Akuttmedisinsk klinikk

Kristian Bartnes

Hjerte-, lunge- og karkirurgisk avdeling

Universitetssykehuset Nord-Norge

9038 Tromsø

Mange hardt tilskadekomne trenger behandling som bare gis ved store sykehus med tilgang til alle kirurgiske spesialiteter, intervensjonsradiologisk service og et avansert intensivmedisinsk tilbud. Stabiliserende kirurgisk behandling ved et lokalsykehus nærmere skadestedet kan være nødvendig. Imidlertid vil verdien av utredning og behandling ved lokalsykehuset i noen tilfeller være marginal, og innsatsen må veies opp mot risikoen ved forsinket transport til sykehus med høyere behandlingsnivå.

Erfaringer fra andre land viser høyere overlevelse for traumepasienter etter innføring av traumesystemer med spesifikke kompetansekrav og klar rollefordeling mellom de ulike ledd i behandlingskjeden (1-3). Det er nylig vedtatt å innføre et nasjonalt traumesystem i Norge (4). Dette blir basert på to sykehusnivåer med ansvar for akuttbehandling av hardt tilskadekomne akuttsykehus og regionale traumesentre. Planen forutsetter at akuttsykehusene kan utføre visse nødkirurgiske prosedyrer rettet mot stabilisering av respirasjon og sirkulasjon (4) (tab 1). Dette er særlig viktig for pasienter som trass i alvorlige skader har potensial for å overleve med høyt funksjonsnivå.

For å belyse behovet for slike inngrep og kartlegge i hvilken grad dagens lokalsykehus utfører dem hos pasienter som blir overført til universitetssykehus, presenterer vi her et komplett toårsmateriale fra vår helseregion. Studien gir grunnlag for spesifikke forslag til forbedring av lokalsykehusenes diagnostikk og behandling og samhandling med universitetssykehuset.

\section{Materiale og metode}

Alle alvorlig tilskadekomne som i perioden 1.1. 2006-31.12. 2007 ble overført fra lokalsykehus til Universitetssykehuset Nord-
Norge i Tromsø innen to døgn etter skaden er inkludert $(5,6)$. Opptaksområdet for sykehuset i Tromsø er de tre nordligste fylkene og Svalbard, og befolkningsgrunnlaget utgjør $12 \%$ av folketallet i Norge.

Pasientene ble identifisert ved gjennomgang av akuttmottakets logg over innleggelser. Data for tidsforløp, diagnostikk, skadeomfang og behandling frem til og med første døgn etter overflyttingen ble kartlagt ved gjennomgang av journalen ved Universitetssykehuset Nord-Norge. Pasientforløpets begynnelse er satt lik tidspunkt for alarmering av lokalsykehuset der dette fremgikk av journalen, ellers benyttet man skadetidspunktet. Tidsintervaller er oppgitt som gjennomsnitt med minimums- og maksimumsverdier.

Skadene ble gradert i henhold til Abbreviated Injury Scale (AIS), som er en anatomisk gradering av skader $\mathrm{i}$ den enkelte kroppsregion. Den går fra 1 (lett skade) til 6 (uforenlig med liv) (5). Det totale skadeomfang hos pasienten ble klassifisert i henhold til Injury Severity Score (ISS), som er summen av kvadratet av AIS-verdien for den alvorligste skaden i hver av de tre hardest skadede anatomiske regioner $(5,6)$. En ISSverdi $>15$ ble regnet som alvorlig skade. ISS-beregningene for samtlige pasienter ble utført av en og samme kirurg basert på diagnoser stilt i løpet av det første døgnet etter innleggelse ved universitetssykehuset.

Stabiliserende kirurgi ble kategorisert i henhold til planen Traumesystem i Norge: forslag til organisering av behandlingen av alvorlig skadde pasienter (4) (tab 1). Bildediagnostiske undersøkelser ble overført elektronisk fra lokalsykehusene og lagret i et elektronisk arkiv (Agfa Impax, Agfa Medical Norway AS). Informasjon om undersøkelser som var utført, men ikke overført til sykehuset i Tromsø, ble innhentet ved henvendelse til de lokale røntgenavdelinger. I hovedsak var lokalsykehusets røntgenbilder

\section{Hovedbudskap}

- Lokalsykehusene bør ha lavere terskel for nødkirurgi

- Bildediagnostikken bør gjennomføres mer planmessig

- Det børvære regelen at lokalsykehuset kontakter universitetssykehuset tidlig ved mottak av hardt tilskadekomne 
Tabell 116 nødkirurgiske prosedyrer fordelt på 14 av 74 pasienter med Injury Severity Score $>15$ ble utført ved lokalsykehus og inntil 24 timer etter overflytting til universitetssykehus

\section{Antall prosedyrer}

Ved Universitetssykehuset

Nødkirurgiske prosedyrer ${ }^{1}$

Innleggelse av thoraxdren

Blodstillende kirurgi i buken, eller i bekkenet med pakking

Torakotomi med avlastning av hjertetamponade

Torakotomi med sutur av enkle stikkskader i hjertet

Torakotomi med sutur av enkle lungeskader

Primærstabilisering av ekstremitetsfrakturer (ekstern fiksasjon)

Sum

I Traumesystem i Norge: forslag til organisering av behandlingen av alvorlig skadde pasienter er det foreslått at man ved alle sykehus som skal ta imot potensielt hardt skadede, må beherske disse prosedyrene (4)

tilgjengelig ved universitetssykehuset før pasienten ankom. Alle CT-undersøkelser og røntgen cervikalcolumna tilsendt fra lokalsykehus og de som var utført første døgn etter overflytting, ble gransket på nytt av to radiologer separat. Ved diskrepans ble konsensus oppnådd ved felles vurdering.

Regional etisk komité og personvernombudet godkjente studien. Av personvernhensyn er enkelte diagnosegrupper slått sammen, og detaljdiskusjoner omkring enkeltpasienter er utelatt.

\section{Resultater}

Materialet omfatter 74 pasienter (58 menn) i alderen 3-88 år (median 32 år) med gjennomsnittlig ISS 24 (spredning 16-57) (fig 1). Vanligste årsak til skade var trafikkulykker $(n=33)$ og fallulykker $(n=29)$. Alle pasientene ble overført til universitetssykehuset med luftambulanse. De var på lokalsykehuset i gjennomsnittlig fem timer (1-46 t), og det tok gjennomsnittlig sju timer $(2-48 \mathrm{t})$ fra første kjente tidspunkt i forløpet til ankomst Universitetssykehuset Nord-Norge i Tromsø (data tilgjengelig for henholdsvis 67 og 65 pasienter).

Hode-/nakkeskader dominerte både totalt og blant de alvorlige skadene (AIS $\geq 3$ ) (tab 2). Åtte pasienter døde under sykehusoppholdet, av henholdsvis nevrotraumer, brannskade og blødning i buk og bekken.

16 nødkirurgiske prosedyrer ble gjennomført hos 14 pasienter. Halvparten av prosedyrene ble utført ved lokalsykehuset - i form av thoraxdreninnleggelse (seks pasienter) og ekstern fiksasjon av frakturer (tab 1).

Seks pasienter gjennomgikk nødkirurgis-

\begin{tabular}{|c|c|}
\hline Antall pasienter & Sykehus \\
\hline றீறிற்றி & Helse Finnmark HF, Klinikk Kirkenes \\
\hline 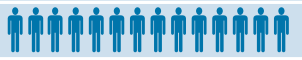 & Helse Finnmark HF, Klinikk Hammerfest \\
\hline 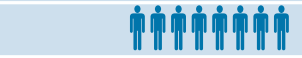 & Universitetssykehuset Nord-Norge HF Harstad \\
\hline 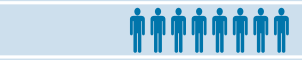 & Universitetssykehuset Nord-Norge HF Narvik \\
\hline 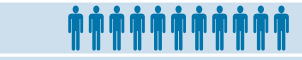 & Nordlandssykehuset HF Vesterålen \\
\hline 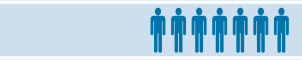 & Nordlandssykehuset HF Lofoten \\
\hline 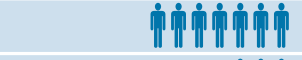 & Nordlandssykehuset HF Bodø \\
\hline 巾ிறிறி & Helgelandssykehuset HF Mo i Rana \\
\hline 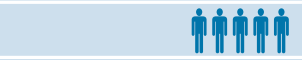 & Helgelandssykehuset HF Sandnessjøen \\
\hline 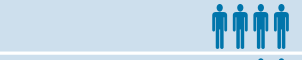 & Helgelandssykehuset HF Mosjøen \\
\hline iிர் & Universitetssykehuset Nord-Norge HF Longyearbyen sykehus \\
\hline$\dot{\|}$ & Gällivarre sjukhus, Sverige \\
\hline
\end{tabular}

Figur 1 Antall alvorlig tilskadekomne (Injury Severity Score > 15) overført fra det enkelte lokalsykehus til universitetssykehuset ke prosedyrer ved ankomst universitetssykehuset. Tre av disse hadde en kjernetemperatur på $34,5^{\circ} \mathrm{C}$ eller lavere. To hadde signifikant hemo-/pneumothorax, om enn med beskjeden påvirkning av respirasjonen. Av disse fikk den ene utført bildediagnostikk av thorax ved lokalsykehuset, men skaden ble ikke erkjent hos noen av disse to før transport til universitetssykehuset. Fire pasienter hadde blødning i buk og/eller bekken som krevde umiddelbar nødkirurgi ved ankomst sykehuset i Tromsø. Hos tre av disse var skadene diagnostiserbare på røntgenbildene som var tatt ved lokalsykehuset. Hos en pasient fremgikk det av innleggelsesskrivet at rask overføring ble prioritert fremfor videre bildediagnostikk og behandling.

Av de 66 hardt tilskadekomne som gjennomgikk CT-undersøkelse ved lokalsykehuset ble det hos 29 ikke utført komplett traumeserie (CT caput, nakke, thorax, abdomen/ bekken). Åtte av 55 pasienter gjennomgikk CT-undersøkelser av thorax og/eller buk/ bekken uten bruk av intravenøst kontrastmiddel, og blant de 62 som fikk utført CT caput, ble det ikke gjort bildediagnostikk av cervikalcolumna hos ti (tab 3). To pasienter ble overført med ikke-erkjente, ustabile nakkefrakturer, om enn med stiv halskrage. Begge ble undersøkt med CT ved lokalsykehuset, uten at det ble utført bildediagnostikk av nakken.

\section{Diskusjon}

I planen for et nasjonalt traumesystem tillegges lokale akuttsykehus en nøkkelrolle i den primære livreddende kirurgiske behandlingen før pasienten overflyttes til et høyere behandlingsnivå (4). Planen forutsetter at akuttsykehusene kan utføre visse nødkirurgiske prosedyrer rettet mot stabilisering av respirasjon og sirkulasjon. De som har størst gevinst av god primærstabilisering og en effektiv evakueringskjede, er pasienter med omfattende skader og behov for overføring til traumesenter. Vi har analysert lokalsykehusenes praksis angående nødkirurgi for denne pasientgruppen før innføring av det nasjonale traumesystemet.

Når det gjaldt de hardt skadede som ble overført til universitetssykehuset, var lokalsykehusenes volum av nødkirurgiske prosedyrer lavt og repertoaret begrenset (kun thoraxdreninnleggelse og bruddfiksasjoner). I gjennomsnitt gikk det 90 døgn mellom hver gang et av regionens lokalsykehus utførte en nødkirurgisk prosedyre før overflytting. Materialet sannsynliggjør at de fleste lokalsykehus får liten erfaring med kirurgisk stabilisering av alvorlig tilskadekomne.

Halvparten av dem som gjennomgikk nødkirurgi, fikk dette utført først etter ankomst universitetssykehuset. Våre data indikerer at den tiden pasienten tilbrakte i lokalsykehuset, i flere tilfeller burde vært utnyttet til kirurgisk stabilisering. Tilstanden til pasienter med udrenert pneumothorax som overflyttes med fly, kan forverres når trykk- 
Tabell 2 Skader hos 74 alvorlig tilskadekomne (Injury Severity Score > 15) overflyttet fra lokalsykehus til universitetssykehus. Verdiene representerer antall pasienter med skade av angitte grad i de ulike regioner

\begin{tabular}{lccc} 
Region & $\begin{array}{c}\text { Antall pasienter } \\
\text { med AlS } 1-2\end{array}$ & $\begin{array}{c}\text { Antall pasienter } \\
\text { med AIS } 3-5\end{array}$ & Sum \\
\hline Hode/nakke & 6 & 56 & 62 \\
\hline Ansikt & 14 & 2 & 16 \\
Thorax & 6 & 35 & 41 \\
\hline Abdomen & 11 & 10 & 21 \\
\hline Bekken og ekstremiteter & 20 & 12 & 32 \\
Eksternt og andre $^{2}$ & 15 & 3 & 18
\end{tabular}

1 AIS (Abbreviated Injury Scale) er en anatomisk skadegradering for de enkelte kroppsregioner. 1 betegner mindre, 2 moderat, 3 alvorlig, 4 svært alvorlig og 5 kritisk skade

2 «Eksternt og andre» betegner skader i hud (laserasjon, kuldeskade, brannskade m.m.), asfyksi, drukning og hypotermi

Tabell 3 Bildediagnostikk utført ved lokalsykehus hos 74 alvorlig tilskadekomne (Injury Severity Score > 15) før overføring til universitetssykehus

Undersøkelse Antall pasienter

\section{CT}

\section{CT multitraumeserie}

Andre kombinasjoner

Sum

Fremstilling av nakken ved mistanke om hodeskade

CT caput kombinert med CT eller røntgen cervikalcolumna

CT caput uten fremstilling av cervikalcolumna

$$
\text { Sum }
$$

Kvalitet på CT thorax/abdomen/bekken

$$
\text { Intravenøs kontrast gitt ved CT thorax og/eller abdomen/bekken }
$$

Ingen intravenøs kontrast gitt ved CT thorax og/eller abdomen/bekken Sum

Åtte pasienter ble ikke unders økt med CT ved lokalsykehuset fordi CT ikke var tilgjengelig ( $n=2$, Longyearbyen sykehus), ikke indisert ( $n=2)$ eller nedprioritert til fordel for rask overføring til universitetsklinikken $(n=4)$

forholdene endres, og noen av pasientene $\mathrm{i}$ materialet hadde behov for hemostatisk nødkirurgi straks ved ankomst universitetssykehuset. Lokalsykehusene kan i noen tilfeller med rette ha prioritert umiddelbar overflytting fremfor kirurgiske tiltak. Imidlertid er transporttiden fra lokal- til universitetssykehuset ofte så lang at kirurgisk stabilisering med thoraxdrenasje, pakking av buken og bekkenstabilisering bør utføres før overflytting, gitt at indikasjonen er truet respirasjon eller pågående blødning.

Majoriteten av de hardt tilskadekomne trengte ikke nødkirurgi, de trengte nevrokirurgisk kompetanse og avansert intensivmedisinsk behandling. Disse kunne med fordel vært overført til universitetssykehuset det.

Lokalsykehusenes bildediagnostikk kan forbedres. Cervikalcolumna bør fremstilles hos alle hardt skadede der det finnes indikasjon for undersøkelse av caput (7). CT-undersøkelser av thorax og abdomen bør systematisk utføres med intravenøs tilførsel av kontrastmiddel, siden dette i betydelig grad øker muligheten til å påvise parenkymskade, karskade og pågående blødning (8). Sammenliknet med klinisk rettede CT-undersøkelser ved høyenergetisk, stump skademekanisme har komplette traumeserier høy sensitivitet og medfører lite ekstra bruk av tid når pasienten først er i CT-maskinen $(9$, 10). Komplette traumeserier bør derfor i tidligere, i noen tilfeller direkte fra skadeste- større grad foretrekkes når man først har bestemt seg for CT-undersøkelse $(9,10)$.

Muligheten for umiddelbar elektronisk overføring av røntgenbilder mellom sykehusene i regionen bør utnyttes til fulle (11). Dette gjelder spesielt når lokalsykehuset ikke har radiolog tilgjengelig.

En vesentlig kvalitetsforbedring kan oppnås dersom lokalsykehusenes traumeledere rutinemessig kontakter det regionale traumesenteret tidlig etter mottak av alvorlig tilskadekomne. I telefonkonferanse med universitetssykehusets traumeleder, akuttmedisinsk kommunikasjonssentral og universitetssykehusets radiolog kan man raskt legge en plan for diagnostikk og behandling lokalt og eventuell overføring til høyere behandlingsnivå. Et nasjonalt traumesystem vil danne et godt rammeverk for å gjennomføre disse forbedringstiltakene.

\section{Oppgitte interessekonflikter: Ingen}

\section{Litteratur}

1. Mullins RJ, Veum-Stone J, Helfand M et al. Outcome of hospitalized injured patients after institution of a trauma system in an urban area. JAMA 1994; 271: 1919-24.

2. Barquist E, Pizzutiello M, Tian L et al. Effect of trauma system maturation on mortality rates in patients with blunt injuries in the Finger Lakes Region of New York State. J Trauma 2000; 49: 63-9.

3. Westhoff J, Hildebrand F, Grotz M et al. Trauma care in Germany. Injury 2003: 34: 674-83.

4. Røise 0. Traumesystem i Norge: forslag til organisering av behandlingen av alvorlig skadde pasienter. Hamar: Helse Øst, 2006.

5. AIS 2005 - Abbreviated Injury Scale 2005. Barrington, IL: Association for the Advancement of Automotive Medicine, 2005.

6. Baker SP, O'Neill B, Haddon W et al. The Injury Severity Score: a method for describing patients with multiple injuries. J Trauma 1974: 14: 187-96.

7. Hanson J, Blackmore C, Mann F et al. Cervical spine injury: a clinical decision rule to identify high risk patients for helical CT screening. AJR Am J Roentgenol 2000; 174: 713-7.

8. Maturen KE, Adusumilli S, Blane CE et al. Contrast-enhanced CT accurately detects haemorrhage in torso trauma: direct comparison with angiography. J Trauma 2007; 62: 740-5.

9. Deunk J, Dekker HM, Brink M et al. The value of indicated computed tomography scans of the chest and abdomen in addition to the conventional radiologic work-up for blunt trauma patients. J Trauma 2007; 63: 757-63.

10. Huber-Wagner S, Lefering R, Qvick LM et al. Effect of whole-body CT during trauma resuscitation on survival: a retrospective, multicentre study. Lancet 2009; 373: 1455-61.

11. Stormo A, Sollid S, Størmer J et al. Neurosurgical teleconsultations in northern Norway. J Telemed Telecare 2004; 10: 135-9.

Manuskriptet ble mottatt 22.6. 2009 og godkjent 22.4. 2010. Medisinsk redaktør Are Brean. 